\title{
Detecting runoff variation in Weihe River basin, China
}

\author{
FAN JINGJING, HUANG QIANG, CUI SHEN \& GUO AIJUN \\ State Key Laboratory Base of Eco-Hydraulic Engineering in Arid Area, Xi'an University of Technology, Xi'an 710048, \\ P. R. China \\ 303432830@qq.com
}

\begin{abstract}
Dramatic changes in hydrological factors in the Weihe River basin are analysed. These changes have exacerbated ecological problems and caused severe water shortages for agriculture, industries and the human population in the region, but their drivers are uncertain. The Mann-Kendall test, accumulated departure analysis, sequential clustering and the sliding t-test methods were used to identify the causes of changes in precipitation and runoff in the Weihe basin. Change-points were identified in the precipitation and runoff records for all sub-catchments. For runoff, the change in trend was most pronounced during the 1990s, whereas changes in precipitation were more prominent earlier. The results indicate that human activities have had a greater impact than climate change on the hydrology of the Weihe basin. These findings have significant implications for the establishment of effective strategies to counter adverse effects of hydrological changes in the catchment.
\end{abstract}

Keywords Weihe River; runoff series; Mann-Kendall test; variation changes; attribution

\section{INTRODUCTION}

Global warming and the increasingly large-scale of human activities (IPCC, 2007) are causing major changes to hydrological cycles of river basins and affecting their physical conditions on a regional scale (Wei, 2007). For example, Barnett et al. (2008) and Szilagyi (2001) highlighted extensive changes to the hydrological cycles of western USA during the last half of the 20th century. In recent decades, hydrological studies have focused on runoff, in particular (Labat et al., 2004; Liu and Xia, 2004; Fraiture, 2007; Hejazi and Moglen, 2007). In northern China, substantial reductions in runoff in recent decades have been observed (inter alia) in the Haihe River catchment (Yang and Tian, 2009), the Yellow River basin (Fu et al., 2004) and the Sanggan River catchment (Zhang 2003). This is a serious concern in the semi-humid and semi-arid regions of the country as they are exacerbating major ecological problems and causing severe water shortages for agriculture, industries and the huge human population (Kling et al., 2012). Thus there is a clear need to identify the causes in order to formulate effective mitigation strategies.

Runoff volumes in a catchment are known to be influenced by numerous factors, including climatic variables (particularly precipitation), human activities, subsurface drainage patterns and various other geographical and hydrological variables (Huang et al., 2003; Chen et al., 2007; Zhang et al.., 2008; Kumar et al., 2009). Changes in any of these variables can profoundly affect runoff, but the main factors driving runoff decline in most Chinese rivers basins are believed to be climate change and human activities (Yang and Tian, 2009, plus other references). Quantifying the impact of climate change on runoff is relatively straightforward, using either traditional regression methods (e.g. Fan et al., 2007) or more complex hydrological models, such as SWAT (Soil and Water Assessment Tool; Yao et al., 2008). In contrast, quantifying changes in runoff caused by human activity is more complex and they are not yet fully understood (Yang and Tian, 2009). However, several methods have been recently developed and applied to detect trends and changes in hydrological records (Wei, 2007; Xie, 2012) and facilitate attempts to identify the main drivers. These include the Mann-Kendall test (Sneyers, 1975; Sulkava et al., 2007; Zhao et al., 2007; Zhang et al., 2008; Fan et al., 2013), Rammer's method (Wei, 2007), the Yamamoto method (Tan et al., 2008), the Pettitt test (Mu et al., 2007), accumulated departure analysis (Zhang et al., 2010), sequential cluster analysis (Yan et al., 2003), and the sliding t-test (Yin et al., 2009).

Although there have been numerous studies on hydrological changes, and several attempts to identify change-points in time series of hydrological data, few have focused on both precipitation and runoff, or attempted to identify the main factors driving the changes. Thus, this study analyses changes in precipitation and runoff, and the factors controlling them, in the Weihe River basin, China, where the water shortage problems mentioned above have increased in recent years. Key objectives 
are to identify change-points in precipitation and runoff series using four methods (the MannKendall test, accumulated departure analysis, sequential cluster analysis and sliding t-test), and the main factors that caused the shifts at the identified change-points.

\section{STUDY AREA AND DATA}

\subsection{Study area}

The Weihe River rises in the Niaoshu hills, Gansu province, and flows into the Yellow River in Shaanxi province. Its basin is located in the semi-humid and semi-arid climate regions and comprises hills, loess terraces and alluvial, mountainous and plateau areas. The basin covers $0.135 \times 10^{6} \mathrm{~km}^{2}\left(103^{\circ} 39^{\prime}-110^{\circ} 37^{\prime} \mathrm{E}\right.$ to $33^{\circ} 42^{\prime}-34^{\circ} 14^{\prime} \mathrm{N}$; Fig. 1) and is divided between three provinces: Shaanxi (49.8\% of the catchment area), Gansu (44.1\%) and Ningxia (6.1\%).

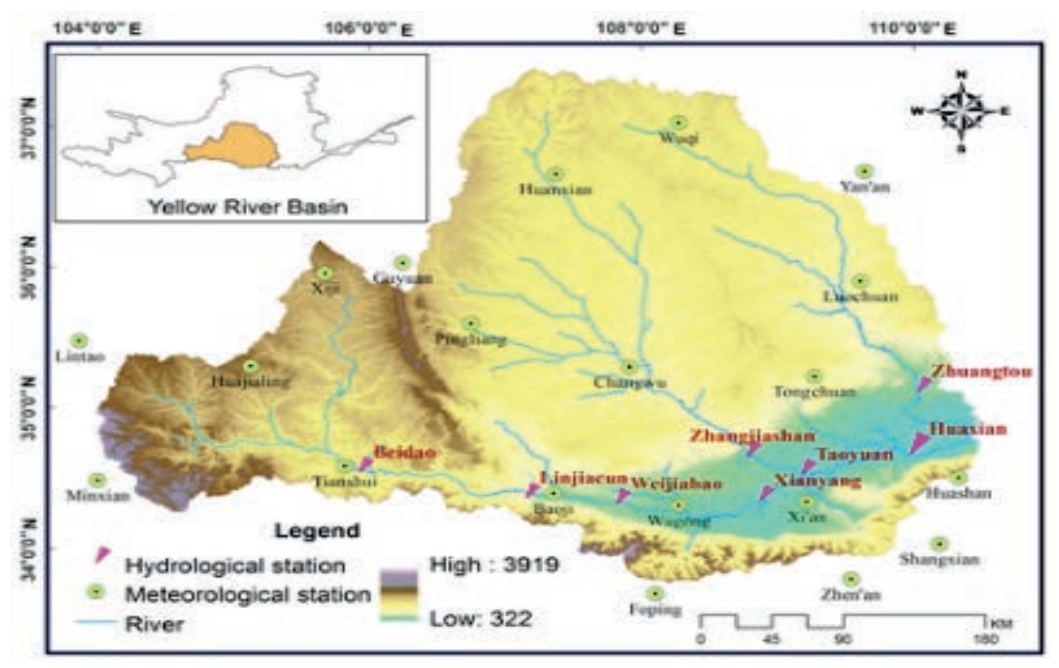

Fig. 1. Map of the Weihe River Basin and its location within the Yellow River basin (insert).

\subsection{Data}

Meteorological and runoff data were collected from 18 precipitation stations and 8 hydrological stations in the Weihe River basin (Fig. 1). Measured variables included areal precipitation and areal potential evaporation and runoff (Fig. 2).

Annual runoff data for January 1960 to December 2010 were provided by six hydrological stations in the mainstream (Beidao, Linjiacun, Weijiapu, Xianyang, Lingtong and Huaxian) of Weihe River. The monthly precipitation data for this period were obtained from the Chinese Meteorological Data Sharing System. Total annual surface precipitation and potential evaporation values (Fig. 2) were calculated from the area-weighted precipitation data collected at the 18 meteorological stations using the Tessellation Polygon Analysis methods.

Area-average precipitation ranged from 366 to $807 \mathrm{~mm} /$ year (mean $494.6 \mathrm{~mm} /$ year), potential evaporation from 720 to $935 \mathrm{~mm} /$ year (Fig. 2). Mean annual runoff was $7.28 \times 10^{6} \mathrm{~m}^{3}$, with a maximum of $208 \times 10^{6} \mathrm{~m}^{3}$ recorded in 1964 and a minimum of $21.00 \times 10^{6} \mathrm{~m}^{3}$ recorded in 1995 .
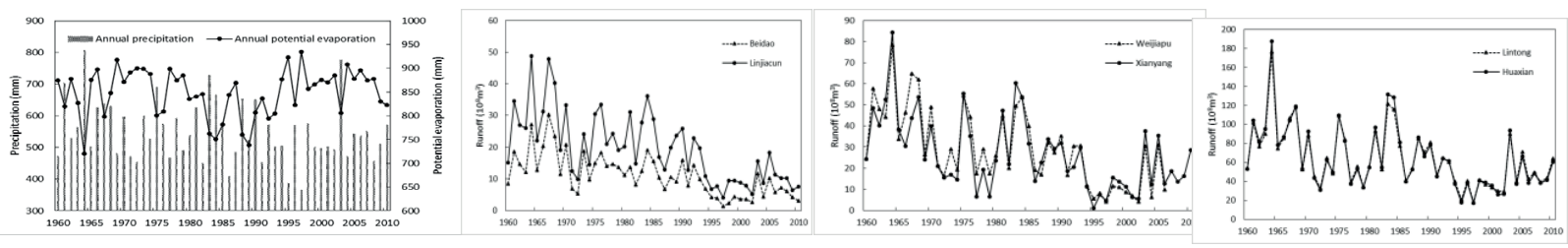

Fig. 2 Area annual precipitation $(\mathrm{mm})$, area potential evaporation $(\mathrm{mm})$, annual runoff $\left(10^{8} \mathrm{~m}^{3}\right)$ in the Weihe River. 


\section{METHODS}

\subsection{Variation points analysis methods}

Four methods are used to analyse the variation points; each method has different attributes.

The sequential Mann-Kendall test (Mann, 1945; Sneyers, 1975) was used to detect variation changes in precipitation recorded at the 18 hydrological stations listed in Table 1 and in runoff (annual, seasonal and monthly) from 1919 to 2011 at the Huaxian hydrological station. The MannKendall test is used to detect trends in time series. The null hypothesis is that the data are independent and randomly distributed, i.e. there is no trend in the dataset. The alternative hypothesis is that there is a monotonic trend in the dataset. Accumulated departure analysis is a commonly applied method that allows for intuitive evaluation of trends in time series. Sequential cluster analysis is a method that clusters observations, while preserving their order. To identify the most likely change-point, $\tau$, an appropriate threshold value is required. The threshold value is optimized by minimizing the sum of quadratic dissimilarity within clusters, while maximizing between-cluster dissimilarity. A shortcoming of this method is that the outcome of the analysis is affected by the sequence endpoints. The moving t-test (MTT) detects climate jumps in a series by assessing the significant differences between averages of two groups of samples. This method has been widely used in China to detect climate jump events.

\subsection{Slope change ratio of cumulative quantity (SCRCQ)}

The difference in curve slope before and after a change-point can be used to calculate contributions of selected factors to the change. If the curve slopes for cumulative precipitation versus time before and after the variation points are $S_{\mathrm{Pa}}$ and $S_{\mathrm{Pb}}$, respectively, and the curve slopes for cumulative runoff versus time before and after the change-point are $S_{\mathrm{Ra}}$ and $S_{\mathrm{Rb}}$, respectively, then the contribution rate from precipitation to runoff, $\mathrm{C}_{\mathrm{P}}(\%)$, after the variation point can be expressed as a percentage of the contribution rate before the change-point:

$$
\mathrm{C}_{\mathrm{P}}=100 \times\left(\left|S_{P a}-S_{P b}\right|-1\right) /\left(\left|S_{R a}-S_{R b}\right|-1\right)
$$

Similarly, the contribution rate from potential evaporation to runoff, $\mathrm{C}_{\mathrm{PE}}(\%)$, after the change-point compared to before the change-point can be expressed as:

$$
\mathrm{C}_{\mathrm{PE}}=100 \times\left(\left|S_{P E a}-S_{P E b}\right|-1\right) /\left(\left|S_{R a}-S_{R b}\right|-1\right)
$$

where $S_{\text {PEa }}$ and $S_{\text {PEa }}$ are the cumulative potential evaporation versus time before and after the variation point.

Thus, the contribution rate from climate change to runoff after the variation point compared to that before the variation point $\left(\mathrm{C}_{\mathrm{C}}, \%\right)$ can be expressed as:

$$
\mathrm{C}_{\mathrm{C}}=\mathrm{C}_{\mathrm{P}}+\mathrm{C}_{\mathrm{PE}}
$$

Based on the principle of water quantity balance, the contribution rate from human activities to runoff $\left(\mathrm{C}_{\mathrm{H}}, \%\right)$ can be expressed as:

$$
\mathrm{C}_{\mathrm{H}}=100-\mathrm{C}_{\mathrm{P}}-\mathrm{C}_{\mathrm{PE}}
$$

\section{RESULTS AND DISCUSSION}

\subsection{Results of Mann-Kendall}

Precipitation time series The Weihe River basin is divided into four sub-basins. The areas covered by the sub-basins and locations of hydrological and meteorological stations are shown in Fig. 3(a). The Mann-Kendall test was used to identify change-points in the annual precipitation series recorded at each station from 1960 to 2011. In total 79 variation points were identified in the Weihe River catchment, 30 of which occurred in the Beidao to Huaxian section of the mainstream. An analysis of the temporal distribution revealed that most change-points (54, nearly $70 \%$ of the 
total) occurred during the 1970s and 1980s (Fig. 3(a)). There was a clear, spatial element to the temporal variation in hydrological change, with most change-points occurring earlier in the southwestern parts and later in the northwestern parts (Fig. 3(b)). There was also a gradual delay in the change-points moving from downstream to upstream.
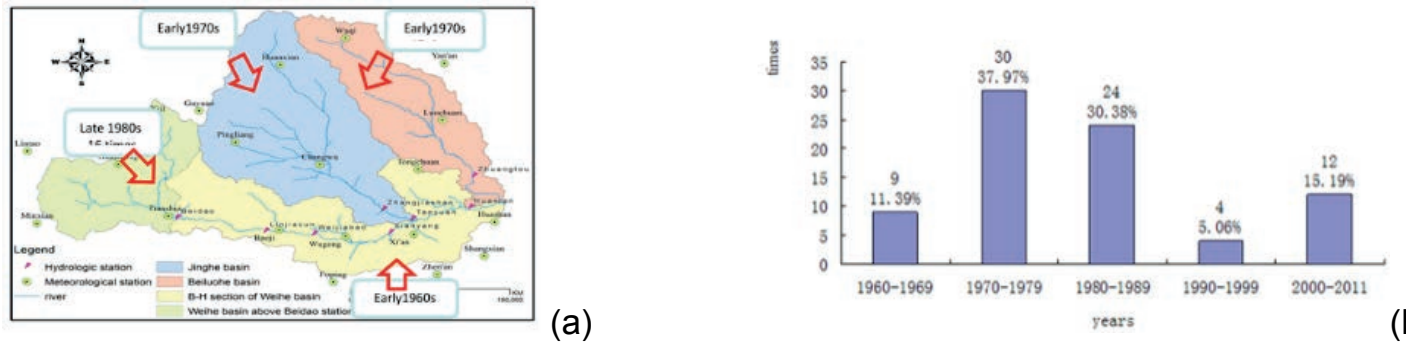

Fig. 3 (a) Time periods change in each sub-basin. (b) Temporal distribution in precipitation records.

Runoff time series The Mann-Kendall test was also used to detect variation points in the runoff records from seven stations along the mainstream Weihe River. Five change-points were found, of which two occurred during the 1980s and three during the 1990s (Table 1). The higher number of change-points in the 1990s suggests that the runoff changes were more dramatic during this decade than during the previous decades.

\subsection{Results of accumulated departure analysis}

Accumulated departure analysis was used to identify change-points in runoff data from each section of the mainstream Weihe River. In total, 11 variation points were identified (Table 2). There was substantial temporal variation in the numbers of these events, with $18 \%$ occurring in the $1960 \mathrm{~s}, 27 \%$ in the $1970 \mathrm{~s}, 27 \%$ in the $1980 \mathrm{~s}$ and $37 \%$ in the $1990 \mathrm{~s}$.

\subsection{Results of sequential cluster analysis}

Sequential cluster analysis was also used to detect change-points in the runoff data from each section of the mainstream Weihe River. In total 17 change-points were identified, with the 1990s having the highest number of events (6) of any decade (Table 3). Thus, changes in runoff were most pronounced during the 1990s.

\subsection{Sliding $T$ test results}

The analysis of runoff data by the sliding t-test identified 17 variation points: four in the 1960s, three in the 1970s, one in the 1980s, five in the 1990s and four in the 2000s (Table 4). The results confirm that the 1990 s was a period of major changes in runoff.

\subsection{Variation results}

Table 5 shows the percentage of runoff variation changes in each decade; the changes in runoff over five decades were analysed using four methods. Each method clearly indicates that hydrological changes in the Weihe River basin occurred most frequently in the 1990s.

\subsection{Attribution}

SCRCQ analysis indicated that climate change contributed substantially less strongly than human activities to the shifts in runoff during the 1990 s (32.9\% and $67.1 \%$, respectively). The contributions from precipitation and potential evaporation were $29.8 \%$ and $3.1 \%$, respectively. In the $2000 \mathrm{~s}$, the influence of human activities further increased, resulting in an $81.1 \%$ contribution, while the contribution from climate change declined to $18.9 \%$, mainly due to a decrease in the contribution of precipitation to $12 \%$. During the same period, the contribution from potential evaporation increased slightly to $6.95 \%$. 
Table 1 Mann-Kendall test results.

\begin{tabular}{ll}
\hline Station & Variation points \\
\hline Linjiacun & - \\
Weijiapu & - \\
Xianyang & 1985 \\
Lintong & 1989 \\
Huaxian & 1990 \\
Zhangjiashan & 1997 \\
Zhuangtou & 1993 \\
\hline
\end{tabular}

Table 2 Accumulated departure analysis results.

\begin{tabular}{lll}
\hline Section & \multicolumn{2}{l}{ Variation points } \\
\hline Above Beidao & 1986 & - \\
Beidao-Linjiacun & 1969 & 1993 \\
Linjiacun-Xianyang & 1971 & 1993 \\
Xianyang-Lintong & 1969 & 1990 \\
Lintong-Huaxian & 1970 & 1986 \\
The entire basin & 1970 & 1993 \\
\hline
\end{tabular}

Table 3 Sequential cluster analysis results.

\begin{tabular}{llll}
\hline Section & \multicolumn{3}{c}{ Variation points } \\
\hline Above Beidao & 1970 & 1985 & 1993 \\
Beidao-Linjiacun & 1968 & 1990 & 1993 \\
Linjiacun-Xianyang & 1968 & 1985 & 1993 \\
Xianyang-Lintong & 1968 & 1990 & - \\
Lintong-Huaxian & 1966 & 1985 & 1988 \\
The entire basin & 1968 & 1985 & 1990 \\
\hline
\end{tabular}

Table 4 Sliding t-test results.

\begin{tabular}{llll}
\hline Section & \multicolumn{4}{c}{ Variation points } \\
\hline Above Beidao & 1970 & 1994 & 2002 \\
Beidao-Linjiacun & 1968 & 1974 & 1994 \\
Linjiacun-Xianyang & 1968 & 1994 & 2002 \\
Xianyang-Lintong & 1968 & 1992 & 2002 \\
Lintong-Huaxian & 1970 & 1988 & - \\
The entire basin & 1968 & 1993 & 2002 \\
\hline
\end{tabular}

Table 5 Variation changes in runoff (\%) over five decades detected using four analytical methods

\begin{tabular}{llllll}
\hline Method & $1960 \mathrm{~s}$ & $1970 \mathrm{~s}$ & $1980 \mathrm{~s}$ & $1990 \mathrm{~s}$ & $2000 \mathrm{~s}$ \\
\hline Mann-Kendall test & & & $40 \%$ & $60 \%$ & \\
Accumulated departure analysis & $18 \%$ & $27 \%$ & $18 \%$ & $36 \%$ & \\
Sequential cluster analysis & $29 \%$ & $6 \%$ & $29 \%$ & $35 \%$ & \\
Sliding t-test & $24 \%$ & $18 \%$ & $6 \%$ & $29 \%$ & $24 \%$ \\
\hline
\end{tabular}

Table 6 Contributions to runoff and slope change ratio of cumulative quantity (SCRCQ) results for the time periods before, during and after shifts in the hydrological regime.

\begin{tabular}{llllllll}
\hline Period & $\mathrm{S}_{\mathrm{R}}$ & $\mathrm{S}_{\mathrm{PE}}$ & $\mathrm{S}_{\mathrm{P}}$ & $\mathrm{C}_{\mathrm{PE}}$ & $\mathrm{C}_{\mathrm{P}}$ & $\mathrm{C}_{\mathrm{H}}$ & $\mathrm{C}_{\mathrm{C}}$ \\
\hline $1960-1989$ & 63.88 & 849.22 & 566.99 & & & & \\
$1990-1999$ & 34.506 & 861.33 & 489.24 & $3.10 \%$ & $29.82 \%$ & $67.08 \%$ & $32.92 \%$ \\
$2000-2010$ & 41.652 & 869.75 & 543.4 & $6.95 \%$ & $11.96 \%$ & $81.10 \%$ & $18.90 \%$ \\
\hline
\end{tabular}

Note: $\mathrm{S}_{\mathrm{R}}, \mathrm{S}_{\mathrm{PE}}, \mathrm{S}_{\mathrm{P}}$ are the curve slopes of cumulative runoff, potential evaporation and precipitation versus time; $\mathrm{C}_{\mathrm{PE}}, \mathrm{C}_{\mathrm{P}}$, $\mathrm{C}_{\mathrm{H}}, \mathrm{C}_{\mathrm{C}}$ are the contribution rates from potential evaporation, precipitation, human activities and climate change to runoff.

The result of calculating the rainfall and streamflow values in the two periods (divided by 1990) is shown in Table 7. At Huaxian station, rainfall had slightly increased, 3\%, while the runoff had a significantly fall, $32.3 \%$, confirming the substantial divergence between changes in precipitation and runoff before and after 1990 .

Total annual consumption increased by $56 \%$ from 2.793 billion $\mathrm{m}^{3}\left(2383 \times 10^{6} \mathrm{~m}^{3}\right.$ of surface water, and $410 \times 10^{6} \mathrm{~m}^{3}$ of groundwater) before $1990 \mathrm{~s}$, to 4.263 billion $\mathrm{m}^{3}\left(2.05\right.$ billion $\mathrm{m}^{3}$ of surface water and 2.213 billion $\mathrm{m}^{3}$ of groundwater) after 1990s. Soil and Water Conservation in Weihe River Basin with an increase of 184 million $\mathrm{m}^{3}$, the average annual runoff from $116 \times 10^{6} \mathrm{~m}^{3}$ (before $1990 \mathrm{~s}$ ) to $300 \times 10^{6} \mathrm{~m}^{3}$ (after 1990s).

Table 7 Changes in mean precipitation $(\mathrm{mm})$ and runoff $\left(108 \mathrm{~m}^{3}\right)$ from 1956-1989 to 1990-2011.

\begin{tabular}{lllllll}
\hline Period & $\begin{array}{l}\text { Mean } \\
\text { precipitation }\end{array}$ & $\begin{array}{l}\text { Mean } \\
\text { change }\end{array}$ & $\begin{array}{l}\text { Percent } \\
\text { change }\end{array}$ & $\begin{array}{l}\text { Mean } \\
\text { runoff }\end{array}$ & $\begin{array}{l}\text { Specific value } \\
\left(10^{8} \mathrm{~m}^{3}\right)\end{array}$ & $\begin{array}{l}\text { Migration } \\
\text { rate }\end{array}$ \\
\hline $1956-1989$ & 506.02 & & & 69.04 & & \\
$1990-2011$ & 521.11 & 15.10 & $3.0 \%$ & 46.73 & -22.31 & $-32.3 \%$ \\
\hline
\end{tabular}

\section{CONCLUSIONS}

Variation points were identified in the precipitation and runoff records for all Weihe River subcatchments, using the Mann-Kendall test, accumulated departure analysis, sequential cluster analysis and sliding t-test. For runoff, the change in trend was most pronounced during the 1990s, 
whereas changes in precipitation were more noticeable earlier in the time series. Human activities were shown to be the main driving force behind these changes. Our findings are in agreement with those of previous studies (e.g. Gao, et al., 2002; Yao et al., 2003; Cui and Cui, 2007) and suggest that human activities have had a greater impact than climate change on the hydrology of the Weihe River basin. Given the changing environment, further work on runoff variation for hydrographic computation in engineering is necessary.

Acknowledgements This work was financially supported by the Natural Science Foundation of China (nos. 51190093, 51179148, 51179149, 51309188), National Key Basic Research 973 of China (no. 2011CB403306), Governmental public industry research special funds for projects (no. 201101043), and Program for New Century Excellent Talents in University. Constructive comments from reviewers are gratefully acknowledged.

\section{REFERENCES}

Cui, B.Y. and Cui, H.Y. (2007) Research of the effect of climate change and human act on the water resources of the Hutuo River Basin. Shanxi Hydro technics, 1, 64-66 (in Chinese).

Barnett, T P. et al. (2008) Human-induced changes in the hydrology of the western United States. Science 319(5866), 1080-1083.

Chen, B. (2007) Climate change and pesticide loss in watershed systems: a simulation modeling study. Journal of Environmental Informatics 10(2), 55-67.

IPCC (2007) Climate Change 2007: The Physical Science Basis. Agenda, 2007, 6(07).

Fraiture, C.D. (2007) Integrated water and food analysis at the global and basin level. An application of water sim. Water Resources Management 21, 185-198

Labat, D. et al. (2004) Evidence for global runoff increase related to climate warming. Advances in Water Resources 27(6), 631-642.

Zhao, F.F. et al. (2007) Huang Long-term trend and abrupt change for major climate variables in the upper Yellow River Basin. Acta Meteorological Sinica 21, 204-214.

Fan, J. et al. (2007) A study of changes in runoff resulting from climate and land cover changes in the Yehe Catchment Agriculturae Bureau Simica 22 (Suppl.), 175-179 (in Chinese).

Fan, J, et al. Detecting Abrupt Change of Streamflow at Lintong Station of Weihe River. Mathematical Problems in Engineering, 2013.

Fengying W. (2007) Modern Technology of Statistics, Diagnosis and Forecast for Climate. Beijing: China Meteorological Press (in Chinese).

Fu G, et al. (2004) Hydro-climatic trends of the Yellow River basin for the last 50 years. Climatic Change 65(1-2), 149-178.

Huang G H. and Chang N B. (2003) The perspectives of environmental informatics and systems analysis. Journal of Environmental Informatics 1(1), 1-7.

Kling H, et al. (2012) Runoff conditions in the upper Danube basin under an ensemble of climate change scenarios. Journal of Hydrology 424, 264-277.

Kumar, S. et al. (2009) Streamflow trends in Indiana: Effects of long term persistence, precipitation and subsurface drains. Journal of Hydrology 374(1), 171-183.

Liu, C.M. and Xia, J. (2004) Global Water System Project (GWSP), China.

Hejazi and Moglen, G.E. (2007) Regression-based approach to low flow prediction in the Maryland Piedmont region under joint climate and land use change. Hydrological Processes 21, 1793-1801.

Q. Yao, et al. (2008) Study on hydrologic response to climate and land cover change in Bayi Reservoir Basin of Taihan Mountain area. Water Saving Irrigation 3, 19-23 (in Chinese).

Yin, Y.H, Wu, S.H. and Chen, G. (2009) Regional difference of climate trend and abrupt climate change in China during 19612006. Journal of Natural Resources 24(12), 2147-2157 (in Chinese).

Sneyers, R. (1975) Sur l'analyse statistique des séries d'observations. WMO Tech Note.

Szilagyi, J. et al. (2001) Evapotranspiration intensifies over the conterminous United States. Journal of Water Resources Planning and Management 127(6), 354-362.

Tan, Zong-kun, et al. (2008) Analysis of climate variation of the Weizhoudao Island in Guangxi Province based on original environment during the last 50 years. Journal of Natural Resources 23(4), 590-599 (in Chinese)

Mu, X.M. et al. (2007) Analysis of the impact of conservation measures on stream flow regime in catchments of the Loess Plateau, China. Hydrology Processes 21, 2124-2134.

Yan Minhua, et al. (2003) Analysis of climate jumps in the Sanjiang Plain. Scientia geogarphica sinica 23(6), 661-667 (in Chinese).

Yang, Y. and Tian, F. (2009) Abrupt change of runoff and its major driving factors in Haihe River Catchment, China. Journal of Hydrology 374(3), 373-383.

Yao, Z. et al. (2003) Analysis of distribution regulation of annual runoff and affection to annual runoff by human activity in the Chaobaihe River. Progress In Geography 6, 008.

Zhang, Q. et al. (2008) Spatial and temporal variability of precipitation maxima during 1960-2005 in the Yangtze River basin and possible association with large-scale circulation. Journal of Hydrology353(3), 215-227.

Zhang Wei, et al. (2010) Interannual tidal range trend in Pearl River Delta. Advances In Water Science 21(1),77-82 (in Chinese). 